\title{
Participatory Carbon Estimation in Community Forest: Methodologies and Learnings
}

\author{
Eak Bahadur Rana' ${ }^{1}$ Him Lal Shrestha² \\ \& Ramesh Silwal ${ }^{3}$
}

\begin{abstract}
Despite the potentiality of community forests to receive payment in turn its contribution of global carbon abatement, inadequate technical difficulties and scientifc base limit the carbon estimation and claim for the payment of carbon compensation in international market. This paper intends to provide an overview of participatory biomass and carbon estimation of CF in Nepal. Synthesized methodologies of national inventory guidelines, IPCC, McDicken and literature estimates were used to execute inventory and calculate the biomass and carbon density. The study found that GPS consumes less time to mapping boundary and laying out sample plots permanently with less systematic and personal errors than using compass survey. The ground based inventory is time consuming, the study concludes that the making capable local users in handling GPS and promoting participatory inventory and carbon calculation avoids the cost thereby make CFs able to claim in access to international carbon market.
\end{abstract}

Key Words: GPS, Biomass, Abatement, Compensation, International carbon market

\section{Introduction}

Forest offers wide range of tangible and intangible benefits which are not adequately recognized in many cases in the current forestry business. Tangible benefits that forest provided includes timber, poles, firewood, dry leaf litter, fodder \& grass, medicines and non-timber forest products. Of them, only a few products have market value. Non-marketability of the products often limits the benefits and choices of forest users. Intangible benefits that forest grants features landscape beauty, biodiversity conservation, carbon sequestration, and improvement of water quality and quantity in terms of environmental servcies. The environmental services of the forest crosses the boarder of forest and community itself, the recognizition of forest benefits are needed to receive by the distant national and international beneficiaries. Lack of valuing the price of such services are the reasons for avoiding to optimize forest benefits to the local users who largely contribute to conserve the forest. Establishment of formal enviromental payment mechanism local and international markets is practised in recent days. Formalization of forest carbon finance through the ratification of Kyoto Protocol in 1997 is promising steps taken towards the consideration of generating win win situation between traditional forest managers and beneficiaries.

\footnotetext{
1 M.Sc. Student, Sustainable Resource Management, Technical University in Munich, Germany

2 Academic Coordinator, Kathmandu Forestry College, Kathmandu, Nepal. hlshrestha@gmail.com

3 B.Sc. Student, Kathmandu Forestry College, Kathmandu, Nepal.vaan_ramesh@hotmail.com
} 
Community Forests (CFs) in Nepal deserves to receive payment for its contribution of carbon conservation with growing forest density and reducing deforestation \& degradation thereby allowing the forest as increased sink and decreased sources of carbon. However, none of CF is recorded to estimate biomass and carbon and prepare forest operational plan with an objective of carbon estimation and monitoring. Associated technical difficulties couple with inadequate scientific information limit the CFs to estimate carbon and claim the payment in international carbon markets.

This paper is a summary of a work involved in the M.Sc. thesis title on "Carbon Trade Possibilities in Community Forest in Nepal". The paper aims to provide an overview of participatory biomass and carbon estimation methodologies in community forests Nepal.

\section{Study Site}

The study was undertaken in Torikhet CF of Dhading district, Nepal (Fig 1). The forest covers an area of 75.57 ha involving 240 households that represents Brhamin, Chhetri, diverse ethnic groups of Tamang, Bhujul, Gurung and schedule castes of Sunar an Sarki. With the facilitation and technical support of forest inventory and development forest management plan of Natural Resource Management Project, the forest was formally handed over as community forest to local community in 1996 . The forest management plan was renewed in 2002 with technical support of RIMS

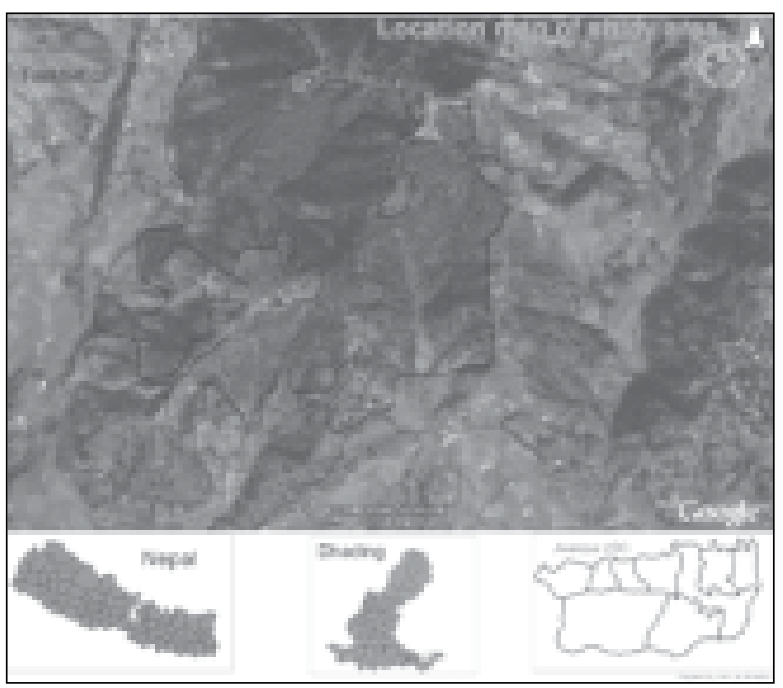

Fig 1: Map showing the location of study Nepal.

\section{Methodologies of the Study}

The study involves both interaction with local users and participatory inventory activities as below.

\section{Group selection and interaction}

Since the idea behind the study was to estimate current level of biomass and carbon as well as to observe the biomass increment trend, the availibility of growing stock data at least of five years back remained basic criteria for selecting the CF. Following the criteria along with williness of users in participating the

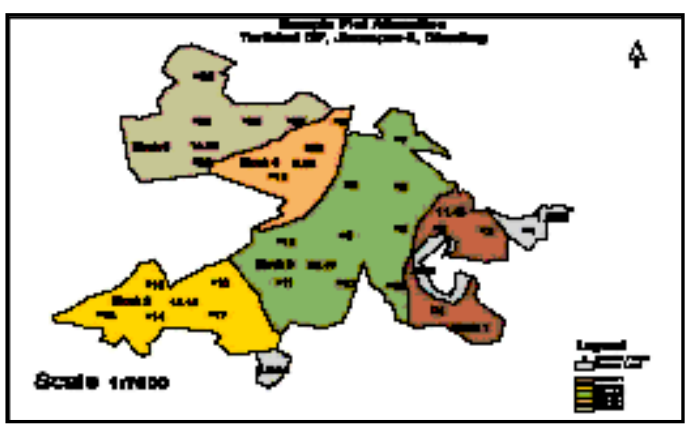

Fig 2: Map showing sample plot defined with GPS 
inventory work, the CF was selected in consultation with RIMS4-Nepal Dhading. A small group discussion with committee members was held initially and community members were informed about the forest carbon sequestration and its contribution to global warming abatement. Their involvment was then asked to provide during inventory work.

\section{Boundary mapping}

The forest was mapped jointly by researcher and community members using GPS and GIS system (Garmin GPS 12 and ArcView 3.x) which was traced onto base maps. For this, entire boundary of the forest was visited and coordinates of each points along the boundary were marked. The coordinates for block division were also marked on the same way in order to demarcate community forest from the individual cultivated land (Shrestha, 2006).

\section{Estimation and layout of sample plot}

One percent of sampling plots were recognized to meet the requirements of survey. Vegetation is largely dominated by the immature Shorea and Pinus trees so the single sample plot area is determined of $300 \mathrm{~m}^{2}$ as described by the National Inventory Guideline (NIG). Area, number and distance between the plots were determined with the formula given in NIG. Once the sample plots determined, it was systematically located in the map using ArcView 3.x and the locational information i.e. latitude and longitude of overlaid sample plots were extracted from map. The plots were then tracked in the field by storing those latitudes and longitudes in the GPS unit and using GO TO function of GPS system (Shrestha, 2006).

\section{Measurement of sample plot}

The sample plots of $1 \%$ sampling intensity was fixed refering to national inventory guideline developed by Department of Forest, Community and Private Forest Division (CPFD, 2000b). Even though the guideline recommended rectangular plots, a circular plot of $300 \mathrm{~m}^{2}(9.77 \mathrm{~m}$ radius) was used to measure the poles and trees within the plot was systematically laid out. Altogether 26 sample plots were laid out. The first plot was located from the $50 \mathrm{~m}$ of the reference. Then the next plot was laid out perpendicularly or straight based on the block shape at defined distance from the previous plot. The location of the each plot was set on Global Positioning System (GPS) unit. With the help of the map and GPS, plots were identified and marked at a similar distance from each other. In order to make it much convenient, the center of the plot was taken a tree (marking with white color) and radius of the circular plot was taken from the center of this tree.

\section{Measurement of trees}

Individual trees greater than $5 \mathrm{~cm}$ dbh (diameter at breast height) and their height were measured and recorded over the whole plot of the $9.77 \mathrm{~m}$ radius $\left(300 \mathrm{~m}^{2}\right)$. Diameter tape was used to

\footnotetext{
${ }^{4}$ Resource Identification and Management System, Nepal is an non-governmental, non-political and non-profit making organization working in the field of community forest in Dhading district, Nepal since 2000.
} 
measure the diameter. Data on each measurement of the sample plot were recorded along with the species name and put in the data collection. The data were later entered into the excel spreadsheet. Species verification in the field was done by three persons representating from local users so as to reduce discrepancy.

\section{Biomass estimation of the forest}

The total average carbon stock per hectare (= carbon density) in the forest is estimated by the following equation:

$\mathrm{C}=\mathrm{C}_{\mathrm{T}}+\mathrm{C}_{\mathrm{FF}}+\mathrm{C}_{\mathrm{SS}}$

Where, $C=$ Average carbon stock per hectare $\mathrm{tCO}_{2} \mathrm{e} \mathrm{ha}^{-1}$

$C_{T}=$ Average carbon stock per hectare in the tree biomass; $\mathrm{tCO}_{2} \mathrm{e} \mathrm{ha}^{-1}>5 \mathrm{~cm}$ dbh

$C_{F F}=$ Average carbon stock per hectare in the forest floor biomass; $\mathrm{tCO}_{2} \mathrm{e} \mathrm{ha}^{-1}$

$C_{S S}=$ Average carbon stock per hectare in the small seedling; $\mathrm{tCO}_{2} \mathrm{e} \mathrm{ha}^{-1}$

\section{Estimation of the biomass of trees}

The national allometry table developed by the Department of Forest, Tree Improvement Seed Center (TISC), was used to calculate the standing biomass. The equation is simplified that requires $\mathrm{dbh}$ as a single input variable to calculate the volume. The biomass tables were prepared for different species but did not cover the whole species present in sampled CFs. So, for the species whose biomass table were not available, the tables of next species almost similar to that species were used. Biomass value was converted to carbon stocks using 0.5 carbon fraction a defualt values (MacDicken, 1997, IPCC, 2006 and Penman 2003) and it was expressed in $\mathrm{t} / \mathrm{ha}$. Carbon is multiplied by $44 / 12$ the ratio in order to convert the carbon to carbon dioxide.

\section{Biomass estimation of small plants and floor materials}

To determine the biomass of small plants $(<5 \mathrm{~cm}$ dbh), subplots of $1 \mathrm{~m}$ radius were demarcated inside the main plot. The grasses and small plants were harvested, weighted and sample of the parts were brought to lab and oven dried at 260 degree celcius until getting the constant weight. Half of the biomass is then determined as the carbon storage of the plant.

The forest floor materials including dry and fresh leaf litter, fruits and flower, green fallen twigs and woods on the floor of $1 \mathrm{~m}$ radius were collected carefully, avoiding contamination with soil and stone particles. The sample of the collection was also brought to the laboratory to 


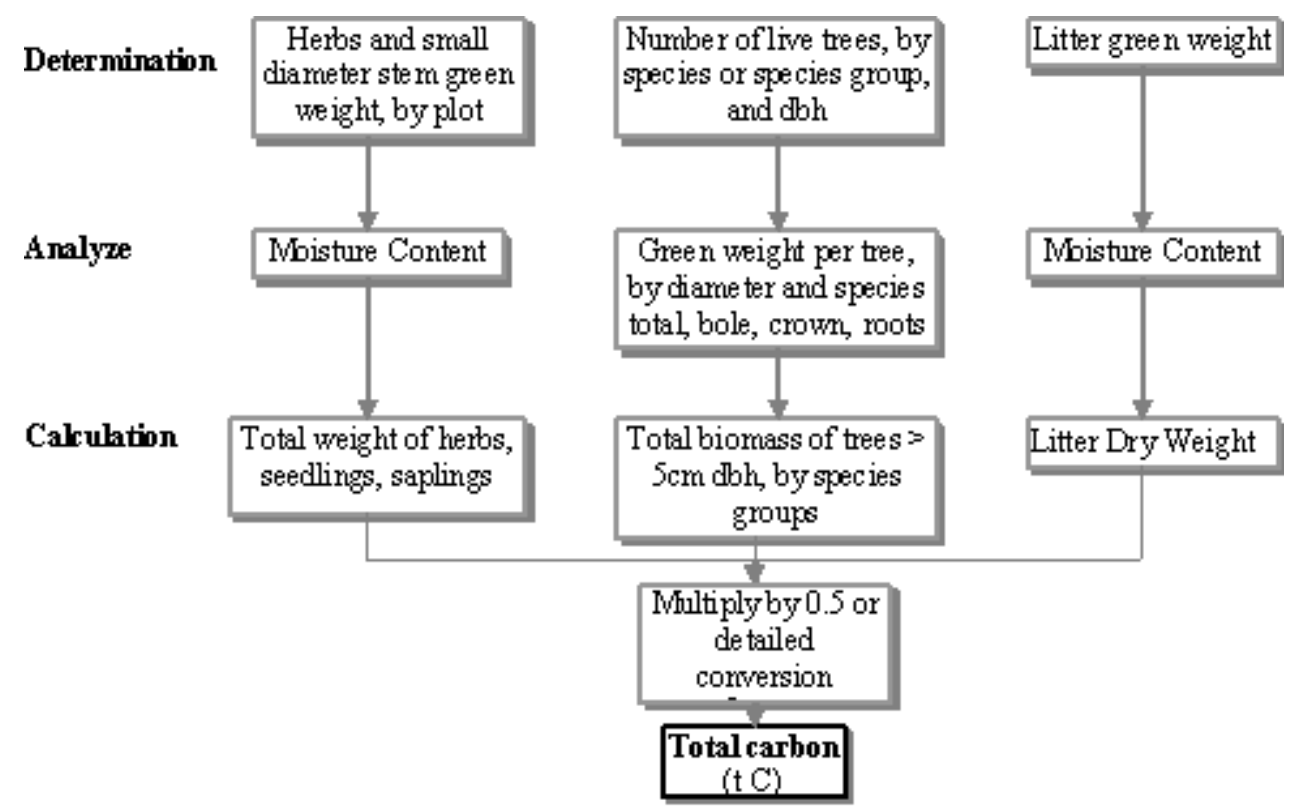

Fig 3: Overall steps and methods of carrying out forest inventory and carbon estimation adapted by McDicken 1997

calculate the oven dry weight. Weight of the $3.1416 \mathrm{~m}^{2}$ was then scaled up to other sample plot and whole forest.

\section{Calculation of below ground biomass}

Below ground biomass was calculated by using simple default value of shoot root ratio for different forest types as recommended by IPCC (2003). We used the shoot root ratio value of $12.5 \%$. The root biomass value is established based on a predictive relationship from extensive literature review as mentioned by Houghton et al., 2001, Achard et al, 2002, Ramankutty et al, 2007.

\section{Estimation of biomass of stem volume}

Growing stock information of CF was collected from the forest management plan developed during CF handed over and the renewal of plan in 1996 and 2002 respectively. During forest hand over and renewal, stem volume was calculated. With the available data of stem volume, living standing biomass of the period was then (including root biomass) calculated by using Biomass Expansion Factor $(B E F)^{5}$. The formula, Total biomass $\left(W_{T}\right)=W_{S}$

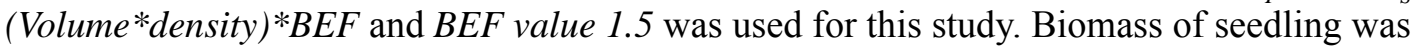
determined from the number of seedling record available on Forest Management Plan. Below ground biomass was calculated by taking default value of $12.5 \%$ of the above ground biomass as explained by McDicken (1997).

\footnotetext{
5 BEF is defined as the ratio of total aboveground oven-dry biomass density of trees with a minimum dbh of $10 \mathrm{~cm}$ or more to the oven-dry biomass density of the inventoried volume (Brown and Lugo 1992). Mean BEF value (1.5) of broadleaved forest 1.74 and conifer 1.3 is used for this study as suggested by Brown and Luge.
} 
Because of unavailability of information of forest floor materials of the last two periods, biomass of forest floor materials including dead wood, dry litters, broken branches, leaves were estimated to be equivalent to $\sim 10-20 \%$ of the above ground forest biomass (trees and seedling biomass) in mature forest explained by Harmon and Sexton, 1996, Delaney et al, 1998, Houghton et al, 2001, Achard et al, 2002. The forest is as such not of mature stage of the studied community forest. It was, therefore, the forest floor materials biomass was determined using the value $14 \%$. Total biomass was then estimated by adding tree biomass, seedling biomass and forest floor biomass. Carbon content was then estimated as thumb rule of $50 \%$ of total biomass $\left(C_{T}=\right.$ $\left.W T^{*} 0.5\right)$.

\section{Findings}

Table 1 presents the forest status of different vegetation parameters in three different periods. Overall biomass and carbon is found increased gradually in three time series.

Table 1: Above and Below Ground Biomass and Carbon Increment Trend over Time in Studied CF

\begin{tabular}{|c|c|c|c|}
\hline \multirow{2}{*}{ Camon Iformationin Studed C F } & \multicolumn{3}{|c|}{ Time Series } \\
\hline & Fime $_{1}(1996)$ & Time $_{2}(2002)$ & Fines 2008$)$ \\
\hline Per ha above ground biomass ( $>5 \mathrm{~cm}$ da) both shoot \& root biomass in $\mathrm{K}_{\mathrm{g}}$ & 34122 & 83480 & 107400 \\
\hline Per ha small seedling ( $<5 \mathrm{~cm}$ ) biomass (ovendry biomass) in $\mathrm{Kg}$ & 5738 & 5540 & 10185 \\
\hline Per ha for est floor materials biomass in $\mathrm{Kg}$ & 11180 & 12463 & 14920 \\
\hline Awerage per ha biomass in $\mathrm{Kg}$ & 91039 & 101483 & 132505 \\
\hline Biomass for totalf orest are a in Kg & 7480705 & 7973554 & 10013432 \\
\hline Cabon seque stration for total are a & 3740353 & 3986777 & 5006716 \\
\hline Carbon seque stration for total are a in torne (tCarbon) & 3740 & 3987 & 5007 \\
\hline Per hatc arbon. & 49,50 & 52,76 & 66.25 \\
\hline
\end{tabular}

Table 2 shows the carbon density for three periods. Per ha tree density was found decreased in recent inventory due to the thinning activities after second inventory. The increment in per ha basal area and total biomass indicates the increased in tree size over the time.

Table 2: Biomass and Carbon Increment Trend over time in studied CF

\begin{tabular}{|c|c|c|c|c|c|}
\hline \multirow{2}{*}{ Biomass' Carb on Mass } & \multicolumn{3}{|c|}{ Carbon Densitiy in Various Time tha $\mathrm{a}^{-1}$} & \multirow{2}{*}{$\begin{array}{c}\text { Mean C } \\
\text { Sequestration rate } \\
\text { tChaper } 5 \text { year }\end{array}$} & \multirow{2}{*}{$\begin{array}{c}\text { Mean C } \\
\text { Sequestration } \\
\text { rate tCha-1 } \mathbf{y r}^{-1}\end{array}$} \\
\hline & $\operatorname{Time}(1996)$ & Time (2002) $^{2}$ & $\mathrm{~T} \mathrm{ime}_{3}(2008)$ & & \\
\hline Perha Basal Area & HA & 1280 & 13,76 & \multirow{4}{*}{6,98} & \multirow{4}{*}{1,40} \\
\hline Per ha Tree Dersity & 918 & 1010 & 967 & & \\
\hline Per ha Biomass in $\mathrm{Kg}$ & 91039,37 & 101483,44 & 132505,39 & & \\
\hline Per ha Carbon Density tha ${ }^{-1}$ & 49,50 & 52,76 & 66,25 & & \\
\hline
\end{tabular}

N A = Irfomation not available

The study found that the use of GPS is less time consuming than use of compass for boundary mapping and designing sample plot. Sample plot established with GPS is dealt permanent for future inventory to identify the increment of biomass even in single plot. GPS served to perform survey with minimum errors avoiding cumulative errors normally occur during the compass survey. Local users knowledge and experiences with basic inventory became easy to handle the GPS with short orientation. 


\section{Conclusion}

The study limits to include soil carbon to its calculation of carbon, though the soil carbon represent significant valuing in forest carbon due to the time and technology constraints in estimating soil carbon. The study team reaffirmed that the ground based forest carbon estimation is time consuming task that requires rigorious effort and thus increase transaction cost. However, developing skills to local users in handling GPS, maitaining data sheet and calculation carbon may help reduc time and cost thereby making CF possible to attain incremental benefits in accessing to international carbon finance. The study thus recommends to make capable local users in handling GPS and avoid the errors, high cost and lengthy time in forest inventory, in general, mapping boundary and laying out sample plot in particicular. The study felt need to implement further study to estimate soil carbon for actual calculation of forest carbon that a CF contribute to carbon sequestration.

\section{References:}

Achard, F., Eva, H.D., Stibig, H. J., Mayaux, P., Gallego, J., Richards, T. and Malingreau, J$P$ (2002): Determination of Deforestation Rates of the World's Human Tropical Forests Science 297 999-1002

Baskota, K., Karki, B.S., Skutsch. M. (2007): Reducing Carbon Emission Through CommunityManaged Forest in the Himalya, International Centre for Integrated Mountain Development, Kathmandu, Nepal.

Brown, S. and Lugo, A. E. (1992): Aboveground biomass estimates for tropical moist forests of the BrazilianAmazon Interciencia 17 8-18

Delany M., Brown, S., Lugo, A.E., Torres-Lezama, A. and Bello Quintero N.(1998): The quantity and Turnover of Dead Wood in Permanent Forest Plots in Six Life Zones of Veneuela Biotropica 30 2-11

DoF (2000): Tree Improvement and Silviculture Component, Government of Nepal, Biomass and Volume Tables with Species Description for Community Forest Management

DoF (2003): Community and Private Forest Division, Revised, Government of Nepal Samudayik Ban Srot Sarbenchhan Margadarsan, Revised

Gibbs, H. K., Brown, S., Niles, J. O., Foley, J. A. (2007): Monitoring and estimating tropical forest carbon stocks: making REDD a reality.

Harmon, M. E., and Sexton, J., (1996): Guidelines for Measurements of Woody Detrius in Forest Ecosystems UL LTER Publication No. 20 US LTER Network Office, University of Washington, Seattle, WA

Houghton, R. A., and Hackler, J. L. (2001): Carbon Flux to the Atmosphere from Land Cover Change: 1850-1980 ORNL/CDIAC-79, NDP.050

Huberman. D. (2007): REDD and Poverty-The social implications of reducing emissions from deforestation in developing countries, a conceptual paper submitted to IUCN.

IPCC (2003):_Good Practice Guidance for Land Use, Land-Use Change and Forestry. Edited by Penman, J and Gytarsky, M and Hiraishi, T and Krug, T and Kruger, D and Pipatti, 
$\mathrm{R}$ and Buendia, $\mathrm{L}$ and Miwa, $\mathrm{K}$ and Ngara, $\mathrm{T}$ and Tanabe, $\mathrm{K}$ and Wagner, $\mathrm{F}$. Intergovernmental Panel on Climate Change.

IPCC (2006). 2006 IPCC Guidelines for National Greenhouse Gas Inventories. Prepared by the National Greenhouse Gas Inventories Programme (eds Eggleston, H.S., Buendia, L., Miwa, K., Ngara, T., Tanabe, K.). Institute for Global Environmental Strategies, Japan.

Laporte, N., Merry, F., Baccini, A., Goetz, S., Stabach, J., Browman, M. (2007): Reduced $\mathrm{CO}_{2}$ Emission from Deforestation and Degradation in the Democratic Republic Congo: A First Look. The Woods Hole Research Center.

MacDicken, K. G. (1997): A Guide to Monitoring Carbon Storage in Forestry and Agroforestry Projects. Winrock International Institute for Agricultural Development, Forest Carbon Monitoring Program.

Maraseni, T.N., Cockfield G., and Apan A. (2002): Valuing Ecosystem Services from Forests: A Multidisplinary Field-Based Approach

Penman, J. (2003): Good Practice Guidance for Land Use, Land Use Change and Forestry. Intergovernmental Panel on Climate Change Working Group-National Greenhouse Gas Inventories Program

Ramankutty, N. (2007): Challenges to estimating carbon Estimations from Tropical Deforestation Global Change Biology 13 51-66

Shrestha, H. L. (2006), Using Global Positioning Systems (GPS) and Geographic Information System (GIS) in Participatory Mapping of Community Forest In Nepal, EJISDC (2006)25,5, p1-11 http://www.ejisdc.org

Torikhet FUG (2002): Torikhet Samudayik Ban Karya Yojana, Torikhet Community Forest User Group, Jiwanpur, Dhading.

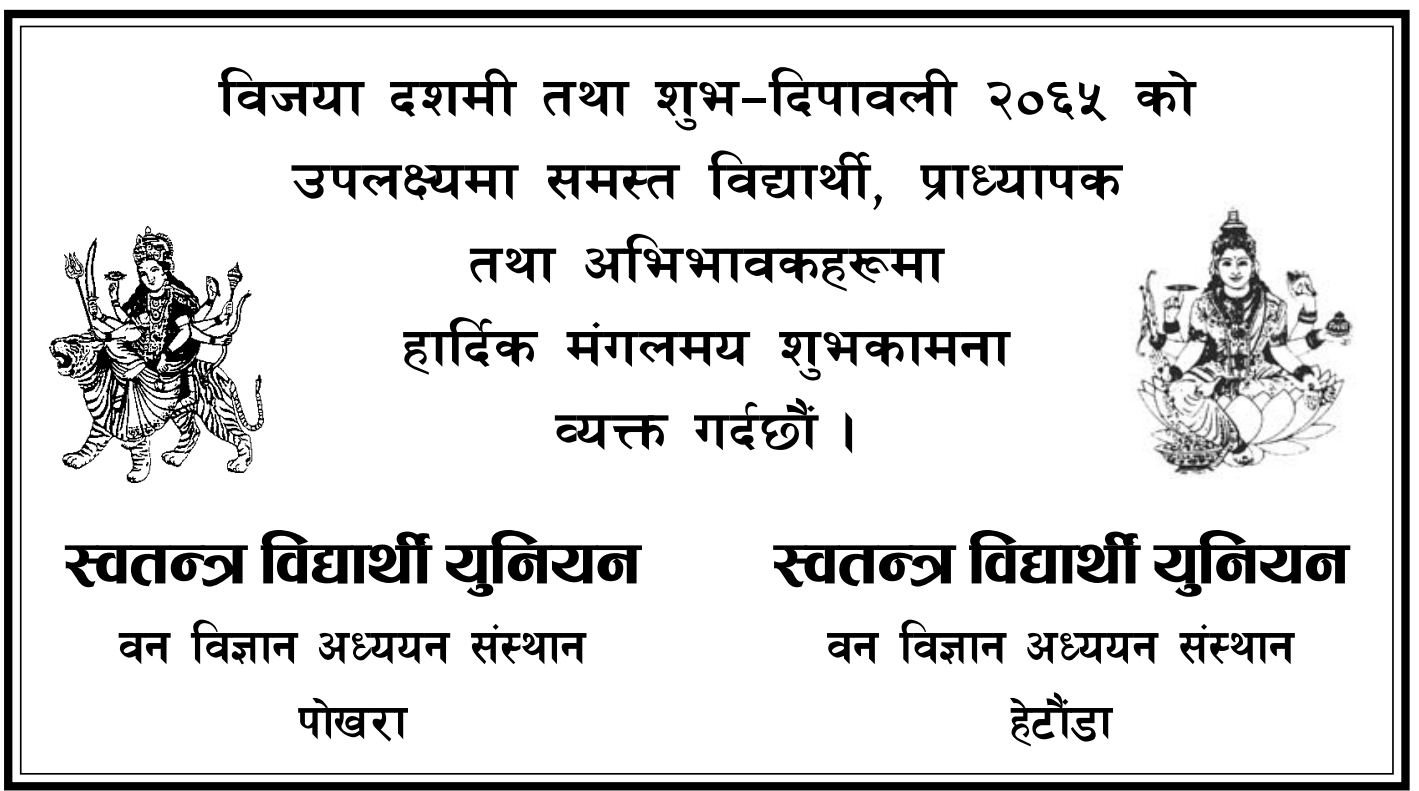

